Diabetologia 10, 197-200 (1974)

(C) by Springer-Verlag 1974

\title{
Trial of Placebo in Long-Term Chlorpropamide-Treated Diabetics
}

\author{
A. Lev-Ran \\ Beilinson Hospital, Petah-Tikva, and Central Endocrine Laboratory of the Sick Fund, Tel-Aviv; Tel-Aviv University \\ Medical School, Tel-Aviv, Israel
}

Received: January 3, 1974, and in revised form: February 5, 1974

Summary. In 50 diabetics on long-term chlorpropamide therapy the drug was substituted by placebo in a single-blind study, and the patients were followed for at least one year. Mean fasting blood glucose (FBG) did not change on placebo as compared to chlorpropamide in 27 patients, significantly decreased in 3 and significantly increased in 20. In the group with the FBG on chlorpropamide less than $130 \mathrm{mg}$ per $100 \mathrm{ml}$, FBG rose on placebo in 3 out of 17 patients (18\%), with FBG $131-160$ $\mathrm{mg}$ per $100 \mathrm{ml}$ in 5 out of 13 patients $(38 \%)$ and with FBG more than $161 \mathrm{mg}$ per $100 \mathrm{ml}$ in 12 out of 20 patients $(60 \%)$. Day-to-day variations were pronounced in all the subgroups. There was no correlation between the changes of the FBG on placebo on one hand and clinical data, im. munoreactive insulin or results of the short glucose tolerance test on the other. It is suggested that the appropriateness of chronic chlorpropamide treatment in diabetes should be periodically questioned and tested.

Key words: Chlorpropamide, sulfonylureas, placebo.
Mild or moderate diabetes is prone to spontaneous remissions and wide fluctuations of the blood glucose. This should have led to periodic re-evaluation of the effectiveness of oral drugs in diabetics, but in fact such studies are very few. Most studies with placebo were restricted to patients starting their oral therapy. It is a widespread practice to give oral drugs to mild or moderate diabetics after a trial with diet alone and later to question their effectiveness only in cases of suspected secondary failure. If, on the other hand, diabetes remains satisfactorily controlled, the drugs are being continued virtually indefinitely. The wisdom of such approach was questioned by several observers $[3,5,15]$, who showed oral antidiabetic drugs to be no more effective in some chronic diabetics than placebo. In view of these studies an attempt was made to substitute placebo for chlorpropamide in a single-blind study in 50 patients treated by this drug for a long time.

\section{Patiens and Methods}

Fifty patients were chosen on the basis of the following criteria: 1 . duration of diabetes at least two years, 2. duration of chlorpropamide therapy at least one year, 3. observation by us on chlorpropamide treatment of at least 6 months. Anamnestic data (in many cases proved by case histories) showed that at least in 41 cases chlorpropamide was started in the past after the failure of diet alone given for the period from 1 month to several years to control diabetes.

There were 27 male and 23 female patients in the group, aged 31 to 72 years (45 of them were over 45 yrs) with the duration of diabetes from 2 to 16 yrs (in 42 patients more than $4 \mathrm{yrs}$ ) and duration of chlorpropamide treatment from 1 to 10 yrs (in 46 patients more than $2 \mathrm{yrs})$. The weight of 24 patients was within $\pm 15 \%$ of the ideal, 26 patients were overweight $16-36 \%$.

During preliminary observation lasting 6 . to 12 months an attempt was made to control diabetes as well as possible with chlorpropamide alone but no attempt was made to stop the drug so that the patients with excellent or good control (fasting blood glucose (FBG) not more than $120 \mathrm{mg}$ per $100 \mathrm{ml}$ ) received $0.125-$ 0.25 per day, those with FBG $121-160 \mathrm{mg}$ per $100 \mathrm{ml}$ $0.375-0.5$ and those with FBG more than $161 \mathrm{mg}$ per $100 \mathrm{ml} 0.5$ of chlorpropamide (Diabinese $\left.{ }^{\circledR}\right)$. FBG and $24 \mathrm{~h}$ glucosuria were determined every $1-2$ weeks for the period of $3-4$ months during the period of relatively stable control. A short glucose tolerance test was performed with a $75 \mathrm{~g}$ oral glucose load and BG and immunoreactive insulin (IRI) determination at 0 and $60 \mathrm{~min}$. Blood glucose was assayed by AutoAnalyser, IRI - with Insulin kits (Radiochemical Centre).

After this period placebo tablets outwardly indistinguishable from chlorpropamide were substituted for the drug. The patients were followed as before. The second short GTI was performed after 2-3 months on placebo.

If there was no changes in FBG, the dose of placebo was slowly (half-a-tablet every two weeks) reduced and finally it was discontinued. If FBG showed significant increase on at least four consecutive visits, chlorpropamide was given again without the patients' knowledge. In those cases in which FBG at the end of the trial remained higher than $160 \mathrm{mg}$ per $100 \mathrm{ml}$, another treatment was given (phenformin, insulin). During the whole trial the patients received no new instructions concerning their diet so that the latter remained virtually unchanged.

Statistical evaluation of the results posed some problem since in many cases FBG on placebo re- 
mained unchanged for 2 to 8 weeks and only later started to rise necessitating return to the drug. Therefore to take into account a mean of all FBG determinations on placebo would have led to unjustified bias in its favour. For this reason we compared in each patient two means of FBG: that of 6 to 9 last determinations on chlorpropamide and that of 4 to 6 last determinations on placebo (when results of the trial became clear). Significance of the differences was tested by the Mann-Whitney U-test (14).

\section{Results}

The main results are presented in the figure. In 27 patients FBG on placebo did not change, in 3 it significantly decreased (!) and in 20 increased. When 30 patients with no increase on placebo are taken together, the difference of the FBG means was $-2 \mathrm{mg}$ per $100 \mathrm{ml}$ (range -30 to $+26 \mathrm{mg}$ per $100 \mathrm{ml}$ ). In 20 patients with FBG increase on placebo the mean difference was +61 (range +31 to +114 ) mg per

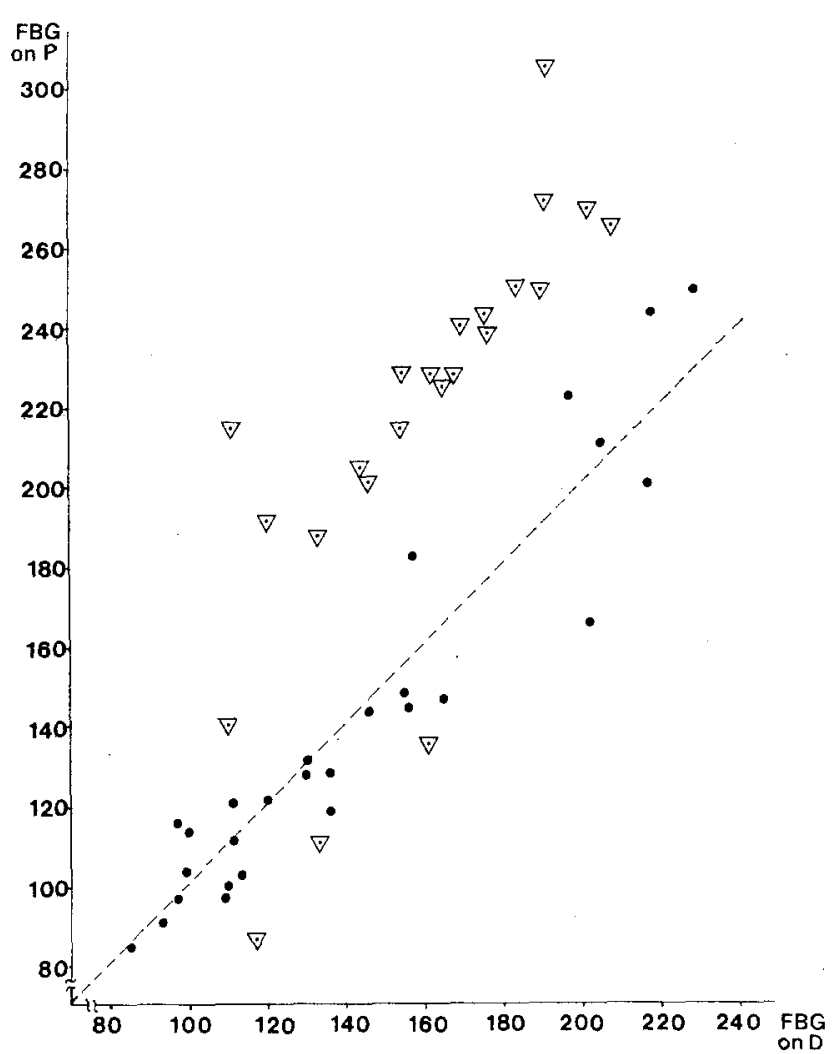

Fig. 1. Mean fasting blood glucose (FBG) levels of patients on chlorpropamide (D) and on placebo (P). On. abscissa - FBG on chlorpropamide, on ordinate - FBG on placebo. Solid points (-) data of patients in whom the difference between the two FBG means was not significant $(P>0.05)$. Triangles with dots $(\nabla)$ - data of patients with significant difference between the FBG means $(P \leqslant 0.05)$
$100 \mathrm{ml}$. The results showed that it was the better controlled group that showed least need of chlorpropamide: when FBG on chlorpropamide was less than $130 \mathrm{mg}$ per $100 \mathrm{ml}, 14$ out of 17 patients ( $82 \%$ ) showed no increase on placebo, so in them the drug could be considered superfluous. In the subgroup with FBG on chlorpropamide 131 to $160 \mathrm{mg}$ per $100 \mathrm{ml}$, 8 out of 13 patients $(62 \%)$ showed no increase on placebo; since the patients were receiving 0.375 to 0.5 of the drug per day, it could be considered fairly effective. Unexpected results were obtained in the subgroup with FBG on chlorpropamide more than $161 \mathrm{mg}$ per $100 \mathrm{ml}$. In these patients the drug could be considered to be ineffective. In fact only 8 out of 20 patients $(40 \%)$ showed no increase of FBG on placebo, so in the rest the drug was considered to be effective, though not enough to control adequately the diabetes. In three patients with FBGs on chlorpropamide of 191, 202 and $208 \mathrm{mg}$ per $100 \mathrm{ml}$, the experiment with placebo was repeated twice within the last 2 years, and on both occasions the results showed significant increase (by 58 to $114 \mathrm{mg}$ per $100 \mathrm{ml}$ ) of the FBG on placebo with subsequent decrease when back on chlorpropamide.

Day-to-day fluctuations of the FBG were quite substantial. In the patients with no increase of FBG on placebo the mean difference between two consecutive FBG determinations was on chlorpropamide $28 \mathrm{mg}$ per $100 \mathrm{ml}$, on placebo $21 \mathrm{mg}$ per $100 \mathrm{ml}$; in those whose FBG on placebo increased - correspondingly 28 and $41 \mathrm{mg}$ per $100 \mathrm{ml}$. In individual cases instability was sometimes much more pronounced, especially in the higher FBG group when the mean difference of each two consecutive FBG determinations reached 50 to $78 \mathrm{mg}$ per $100 \mathrm{ml}$.

Increase of FBG on placebo, when it accurred, took usually several weeks. In only 6 out of 20 patients FBG on placebo increased within the first month, in 8 after $1-2$ months, in $6-$ only after $2-4$ months. This fact stresses the necessity of waiting several months before drawing definite conclusions.

FBG changes on placebo did not correlate with age of the patients, age of onset of diabetes, duration of diabetes or of chlorpropamide treatment, presence of obesity or retinopathy. Neither the IRI determination nor results of the short GTT provided any elue to results of the placebo trial. Results of the short GTT are presented in the table. Patients with higher FBG and no further increase on placebo as well as the patients with increase of $\mathrm{FBG}$ on placebo showed no response of IRI to the glucose load. Individual variations within each subgroup were so great that GTT provided no basis for predicting results of the placebo trial.

Weight changes in patients whose FBG increased on placebo depended partly on the degree of the loss of control of diabetes. In patients with no increase of FBG on placebo in 9 out of 30 patients there was loss of weight $(1.5$ to $3 \mathrm{~kg}$ ), in others the weight remained constant. 
The patients not controlled by diet alone or by chlorpropamide were given another form of treatment. As an acceptable level of $\mathrm{FBG}$ on this stage we arbitrarily chose $160 \mathrm{mg}$ per $100 \mathrm{ml}$, so that patients with lower FBG remained on diet alone. One year after the beginning of the trial the treatment was as follows: diet alone 24 patients, chlorpropamide 7 , chlorpropamide + phenformin 10, insulin 9 . Forty-seven of the patients were satisfactorily controlled, in 3 control was bad, since they refused insulin and FBG remained high on chlorpropamide + phenformin (their FBG increased on placebo, so such a treatment was nevertheless probably better than diet alone). ment, obesity or degree of previous control. In this respect our results correspond to those of Tomkins and Bloom.

Exactly how many of long-term sulfonylureatreated patients can be adequately controlled by diet alone depends on the accepted standards of "good control" and composition of the group under trial. Most important is the fact that in quite a few patients sulfonylureas are inappropriately prescribed and are often continued in patients who could be controlled by diet alone or in those who are no longer responding. In our group, of 17 patients with FBG on chlorpropamide less than $130 \mathrm{mg}$ per $100 \mathrm{ml}, 14$ continued to be as well

Table 1. Blood glucose and immunoreactive insulin (IRI) in patients on chlorpropamide and placebo



\section{Discussion}

Mild and moderate diabetics treated by oral drugs have seldom been subjects for control studies with placebo, especially not at the start of the treatment. Crowley et al. [5] gave tolbutamide to patients who had failed on diet alone and after 6 months substituted it with placebo. Out of 30 diabeties 22 remained well controlled for 1 to 8 months. Bloom [3] found that after 6 weeks on tolbutamide 53 patients out of 78 did not need the drug any more. Katz and Bissel [10] comparing chlorpropamide, tolbutamide and placebo in a double-blind trial found placebo initially effective in 12 patients out of 57 (though in 5 of them blood glucose rose within the next 6 months). In all these studies placebo was given at the start or after only a short period of treatment with sulfonylureas. Tomkins and Bloom [15] tried placebo in patients that had been treated for a long time by oral drugs. In the group treated with sulfonylureas only, placebo caused no deterioration in the control of 10 out of 32 patients; there was no correlation with the duration of treat- controlled on placebo. Therefore it seems desirable and important to re-evaluate periodically the appropriateness of the treatment. In this respect two considerations should be kept in mind. Firstly, in the great majority of the patients FBG remained unchanged some weeks after the discontinuing the sulfonylurea, so that the final decision has to be postponed for 6 months. Secondly, spontaneous fluctuations of blood glucose are quite substantial. The importance of such a variability was stressed by Jackson et al. [9]. The fluctuations forbear hasty changes of the treatment on the shaky basis of a single high FBG value. Because of this, we fully agree with Fajans [6] that a patient should be started on a sulfonylurea only if a long-term observation on diet alone shows no improvement of glucose tolerance. Balsam et al. [2] observed in children with latent diabetes better glucose tolerance on diet alone than on tolbutamide.

Most observers found that long-term chlorpropamide treatment did not result in an increase of the basal concentration of IRI, or a greater IRI response to glucose; on the other hand, control of diabetes by 
the drug did not depend on the increase in IRI and was quite clear even in some cases with very. low IRI values $[4,7,11]$. Even in normal dogs improvements in glucose tolerance after $50 \mathrm{mg}$ of chlorpropamide were not due to absolute increment in plasma IRI response to glucose [12]. Our data point to the same conclusion showing no changes in IRI response after cessation of chlorpropamide. We cannot, however, exclude the possibility that the drug improved the earliest phase (at $5 \mathrm{~min}$ ) of glucose-induced insulin release as was shown after 3 months of chlorpropamide treatment [8]. We do not discuss effects of other sulfonylureas since there may be substantial differences between different preparations in this respect [1].

Why chlorpropamide did not cause hypoglycemia in those patients in whom it was superfluous is not clear. Contrainsulin mechanisms may be responsible or some other factor, e.g. changed metabolism of the drug. The second suggestion seems plausible in view of the lower chlorpropamide recovery in urine in patients with poor response to the drug [13].

The present study as well as that of Tomkins and Bloom [15] stresses the advisability of periodic reevaluation of the chronic oral therapy in diabetics in order to avoid unnecessary medication in many of them.

Acknowledgements. Diabinese-Placebo was kindly supplied by Pfizer Corp. through the courtesy of Preminger Co., Tel-Aviv. Thanks are due to Leah Ratt, M. Sci. for her help in IRI determinations.

\section{References}

1. Aiello, C., Turner, D., Aparicio, N.J.I., de Turner, E. A., Vazquez, A.: Plasma insulin and glucose levels in diabeties treated with glibenclamide and chlorpropamide. Acta diabet. lat. 10, 30-53 (1973)

2. Balsam, M. J., Kaye, R., Baker, L. : Chemical diabetes in children: tolbutamide experience. Metabolism 22, $393-397$ (1973)

3. Bloom, A.: Remission in diabetes. Brit. med. J. 1959 II, $731-734$
4. Chu, P.-C., Conway, M.J., Krouse, H.A., Goodner, C.J.: The pattern of response of plasma insulin and glucose to meals and fasting during ehlorpropamide therapy. Ann. int. med. 68, $757-769$ (1968)

5. Crowley, M.F., Wolff, F.W., Bloom, A.: Tolbutamide in diabetes. Some clinical and biochemical studies. Brit. med. J. 1957 II, 327-331

6. Fajans, S. S.: Treatment of chemical diabetes mellitus with sulfonylurea compounds. Metabolism 22, 373$376(1973)$

7. Fox, O.J., McAdams, G.L., Boshell, B.R.: Effect of sulfonylureas on insulin secretion and insulin reserve. Clin. res. 15, $43(1967)$

8. Hecht, A., Gershberg, H., Hulse, M.: Effect of chlorpropamide treatment on insulin secretion in diabetics: its relationship to the hypoglycemic effect. Metabolism 22, 723-733 (1973)

9. Jackson, W.P.U., Kalk, J., Whisson, A., Hardcastle, A., Toyer, M.G.: Glucose intolerance retested. The importance of variability and a vindication of restriction of dietary carbohydrate. S. Afr. med. J. 46, 2065-2071 (1972)

10. Katz, H.M., Bissel, G.: Blood sugar lowering effects of chlorpropamide and tolbutamide. A double blind cooperative study. Diabetes 14, 650-657 (1965)

11. Reaven, G., Dray, J.: Effect of chlorpropamide on serum glucose and immunoreactive insulin concentrations in patients with maturity-onset diabetes mellitus. Diabetes 16, 487-492 (1967)

12. Reaven, G.M., Lindley, T.S., Weisinger, J.R., Swenson, R.S.: A paradoxical effect of chlorpropamide on the plasma glucose and immunoreactive insulin response to intravenous glucose in normal dogs. Diabetes 22, 367-371 (1973)

13. Sheldon, J., Anderson, J., Stoner, L.: Serum concentration and urinary excretion of oral sulfonylurea compounds. Relation to diabetic control. Diabetes 14, $362-367(1965)$

14. Siegel, S.: Nonparametric statistics, p. 116-127. New York: Mc Graw-Hill Book Co. 1956

15. Tomkins, A.M., Bloom, A.: Assessment of the need for continued oral therapy in diabetes. Brit. med. J. 1972 I, $649-651$

Prof. A. Lev-Ran

7, Ha-Amoraim St.

Ramat-Aviv

Tel-Aviv

Israel 